\title{
Non-small cell lung cancer
}

This patient describes his experience of multidisciplinary care after his diagnosis of non-small cell lung cancer when he was 15 years old

\author{
Andrew Hill patient ${ }^{1}$, Patricia Fisher consultant clinical oncologist ${ }^{2}$, Dan Yeomanson consultant \\ paediatric and TYA oncologist ${ }^{3}$
}

${ }^{1}$ Sheffield, UK; ${ }^{2}$ Weston Park Hospital, Sheffield S10 2SJ; ${ }^{3}$ Sheffield Children's Hospital, Sheffield S10 2TH

\begin{abstract}
This is one of a series of occasional articles by patients about their experiences that offer lessons to doctors. The BMJ welcomes contributions to the series. Please contact Peter Lapsley (plapsley@bmj.com) for guidance.
\end{abstract}

As a 15 year old in a children's hospital, and then a 16 year old in an adult hospital, I am familiar with feeling out of place, but, thanks to an amazing team of medical staff from various disciplines and hospitals who were willing to speak to each other and with me, my experience has been far better than it otherwise would have been.

After having had a persistent cough and feeling tired for around two months, I finally went to see a doctor at my general practice twice in two weeks. Both times I was told that I just had a chest infection and was sent away with an inhaler and corticosteroids, but, after another week with worsening symptoms, I went back to see my own GP, who diagnosed a pneumothorax and sent me to Sheffield Children's Hospital for an x ray and treatment. Given my worsening condition over this time, the decision to send me for further tests could have been taken sooner.

The $\mathrm{x}$ ray showed a mass in my lung. I had my chest drained and was sent home and told to return to clinic the next day, where I saw a distressingly large number of doctors and was told that I needed to be admitted overnight to have a chest drain inserted and my condition monitored. This one night turned into three weeks.

During those three weeks, I spent time on four wards in two hospitals, had four operations, and attracted the interest of what felt like half the hospital, but, thanks to these doctors and hospitals all working together effectively, my stay in hospital was as short and painless as it could have been. In fact, I'd go as far as to say I quite enjoyed it.

I asked the doctors to be frank with me, and they were. They respected that I wasn't a child and were honest with me; to the point that on my third day in hospital I was warned that the mass might be malignant and that this was what they were trying to confirm. This might have been hard for a 15 year old to take, but it was better than having information kept from me. However, I have since discovered that some decisions were taken behind my back, and some information was withheld. I thought I was being told everything, and for this not to be true dents my faith in my doctors; people who I've always trusted and spoken to on my own, without my parents, and asked whatever I wanted to. I thought I knew the whole picture, and for this not to be true hurts. I trusted my doctors, but it feels that they didn't trust me.

It was two days before Christmas when I was diagnosed, and I'd been out of hospital for five days. Being told I had lung cancer was unexpected, and I shut down emotionally. I couldn't express emotion, I just sat there in silence; but the consultants present knew how to deal with me, a child. They didn't throw information at me or pity me, they let me take the lead, be told what I wanted to know. This prevented the situation from becoming emotionally overwhelming. My family also didn't know how to react and just carried on as normal, avoiding the elephant in the room. The fact that a treatment plan was in place provided valuable certainty in a situation where I found myself asking many deep questions.

One of the main choices I made on that day was the decision that the big picture didn't matter. I didn't want to know my prognosis; I just wanted to get on with facing the challenges that treatment posed. Everybody respected this request and let me deal with my problems how I wanted to, they always helped, but the best person was in control-me.

During five months of chemotherapy, I faced many typical challenges, but my hardest task was keeping up with my education. With GCSEs to sit in June and ambitions to make it to university, I battled hard to attend school as much as possible. This was aided by a supportive school and by doctors who spoke with my school and appreciated that education was important to me and was something I enjoyed. My school friends acted 
as if nothing was going on, which provided normality and an escape, but they were always there for me.

I also turned 16 and moved from the care of Sheffield Children's Hospital to Weston Park Hospital. This was my choice, and, had it not been for the Teenage Cancer Trust Unit, I wouldn't have moved. Although adult doctors had aided my care at the Children's Hospital, the move to an adult environment presented challenges. My adult consultant's average patient age was 70, so dealing with a teenager was hard at first. We didn't see eye to eye, and I didn't know how to speak with her, just as she didn't know how to deal with me. This made it awkward initially, but in time we sussed each other out and now get along well.

During radiotherapy, I had painful and long lasting side effects, but I didn't have to be admitted. This is mostly thanks to my GP and local pharmacy who prescribed and provided the medicine I needed when asked to by the hospital. This meant that, instead of having to go to the hospital to pick up medicine, I could pick it up locally. This was of great help to me as I didn't want to go to, or feel like going, to hospital for any reason.

Despite initially not wanting to know about my prognosis, after chemotherapy and before my exams and radiotherapy, it began to prey on my mind, and I asked my consultant for a direct answer. I was told that at diagnosis I was given a year to live, but, after the unexpectedly successful chemotherapy, they now don't know what my cancer will do. I found dealing with a definite time limit alarmingly straightforward and simple, but when that day came and passed I have been left feeling stuck in limbo. Everybody around me has been delighted at how I've done and always comments how well I look, but I don't feel it and I never have. This prognostic uncertainty will always be with me, and even now, two years on, it is at the root of the depression that I'm fighting and often leads me to hoping for the disease to return. This last point often confuses people, but those who understand this view are those who I can really confide in and open up to.

My care after treatment has been focused around one person, a teenage and young adult cancer specialist nurse. She has been a "one stop shop" for all my needs. Whenever I have had any problems, mental or physical, she has been there and been able to reassure me and find the person who can help. She has also been available to my family, to look after them while their "little boy" was ill. This all round, continuous care for me and my family has been an amazing asset, and she is someone who I've always trusted and provides a much needed friendly face whenever I'm in hospital.

My adventure has been long and hard, but-thanks to my friends, family, and all the people I have come across in the medical world being so wonderful to me and doing their best to accommodate a grumpy teenager-it could have been a lot worse. The past two years have shaped me as a person and will never be forgotten.

\section{Competing interests: None declared.}

Provenance and peer review: Not commissioned; not externally peer reviewed.

Accepted: 06 April 2012

Cite this as: BMJ 2012;345:e6443

(๑) BMJ Publishing Group Ltd 2012 


\section{Clinicians' perspectives}

When Andrew presented to the Sheffield Children's Hospital with an apparently spontaneous pneumothorax, the main concern was to rule out Marfan's syndrome. However, close review of the post-aspiration film identified a hilar mass, which was subsequently shown on computed tomography to be obstructing the left main bronchus.

Recognising that malignancy was possible, but expecting pathology commonly seen in teenage and young adult patients, Andrew's doctors started looking for evidence to support a diagnosis of lymphoma or germ cell tumour. Subsequent abdominal computed tomography showed a large retroperitoneal abnormality, which was far more accessible than the hilar mass. Biopsy showed this to be an unrelated lymphangioma, and it became clear that the mediastinal mass would have to be sampled.

Things became much more complicated when this result came back: non-small cell lung cancer is not a paediatric diagnosis, and adult lung cancer specialists do not look after teenagers. It was immediately clear that Andrew would need a combination of age appropriate and site specific expertise, as recommended in the 2005 NICE guidance (Improving Outcomes for Children and Young People with Cancer). The challenge would be in delivering this on a bespoke basis in two separate NHS hospital trusts, and doing so without delay.

Fortunately a teenage and young adult service, which works across both trusts, already existed. It was relatively easy to identify the most suitable clinicians from both a teenage and young adult perspective and a lung cancer perspective, although we had never met each other before. Both of us recall how far out of our comfort zones Andrew's diagnosis took us, and our first task was to sort out who was going to lead on the individual components of his care.

Key to the whole process was close liaison between all the teams, paediatric and adult, that became involved in Andrew's care as his diagnosis became clear and treatment began.

Joint consultations were the visible manifestation of detailed discussions that went on before each step of the process, as Andrew's care was passed from paediatric surgeon to paediatric oncologist and, after Andrew turned 16, on to his adult oncologist. Ensuring that each transition was a smooth process, rather than a one-off event, meant that joint consultations went on for three or four months, initially at the Sheffield Children's Hospital and then on the Teenage Cancer Trust Unit at Weston Park Hospital. Reflecting on the transition, we realise that, although Andrew was the main beneficiary, we both learnt from the experience.

We have also learnt from Andrew-his frankness about the difficulties he has faced since his disease went into remission and the specific issues he raises about prognostication are important. As oncologists, we are both acutely conscious of the difficulties in predicting outcome and take great care when discussing life expectancy with our patients. Andrew reminds us that what we think we have said may not be what the patient hears, but it is what the patient hears that shapes his or her life. All of us should take note.

Dan Yeomanson and Patricia Fisher

\section{Useful resources}

Macmillan Cancer Support (www.macmillan.org.uk)—A British charity that provides practical, medical, and financial support for people with cancer and campaigns for better cancer care

Teenage Cancer Trust (www.teenagecancertrust.org)—A British charity devoted to improving the lives of teenagers and young adults with cancer

CanTeen (www.canteen.org.au)-The Australian organisation for young people living with cancer

LIVESTRONG (www.livestrong.org)—Part of the Lance Armstrong Foundation, a US organisation providing support for cancer patients and their carers, family, and friends 